PP-021

A SPECIAL STUDY MODULE IN MEDICAL EDUCATION: THE INVESTIGAION OF POSSIBLE PROTECTIVE EFFECTS OF LIPOIC ACID ON P38 MAPK SIGNALING PATHWAY AGAINST CISPLATIN INDUCED TESTICULAR DAMAGE IN RATS

Sedenay Sifil ${ }^{1^{*}}$, Beyza Sezer ${ }^{1^{*}}$, Hatice Çakırlar ${ }^{1^{*}}$, Elif Ekin Tunga ${ }^{1^{*}}$, Cemre Ural ${ }^{2}$, Ayşe Koçak², Pınar Akokay ${ }^{3}$, Duygu Harmancı ${ }^{2}$, Çetin Pekçetin $^{3}$, Zahide Çavdar ${ }^{2,4}$

${ }^{1}$ Dokuz Eylul University, School of Medicine, SSM group students in year 2, İzmir, Turkey

${ }^{2}$ Dokuz Eylul University, Helath Science Institution, Molecular Medicine Department, İzmir, Turkey

${ }^{3}$ Dokuz Eylul University, School of Medicine, Histology and Embryology Department, ${ }^{4}$ Dokuz Eylul University, School of Medicine, Research Laboratory, *SSM group students contributed equally to this study cemreural@gmail.com

Special Study Modules (SSM) are integrated into the first three years of Dokuz Eylul University School of Medicine and are offered in four different fields: literature search, clinical research, laboratory research, and social responsibility SSMs. We planned a SSM for four second-year students in the category of laboratory research. The objectives of this SSM were to train the students in independent learning, the basic principles of scientific methodology and written and oral presentation of the results of scientific research. With this aim, the testis tissues from our previous study performed on cisplatin-induced testicular damage model in rats were used in this SSM. Total p38 MAPK and phosphorylated p38 (p-p38) signaling pathway protein expression and cellular localization were assessed by western blotting and immunohistochemistry, respectively. Compared to the control group, total p38 and p-p38 protein expression increased significantly in the cisplatin-induced damage group. This increase was significantly decreased with LA. The distribution detected in seminiferous tubules in immunohistochemical findings was similar to western blot findings. After finishing the project, the students prepared a written report and presented orally their results at the final of the SSMs period. The student feedback results showed that the students faced, at the beginning, a bit of difficulty reading the scientific articles. However, they felt that they learned how to read and discuss the scientific articles, they were happy with the wet laboratory, and the research skills that they acquired. Additionally, students gained awareness related to molecular mechanisms underlying diseases with this SSM. The tutors found this educational activity fruitful and rewarding.

\section{PP-022 \\ ACADEMIC PERFORMANCE OF INTERNATIONAL STUDENTS IN DENTAL BIOCHEMISTRY COURSE}

Rabia Semsi ${ }^{1}$, Erdal Ergünol ${ }^{2}$, Aylin Sepici Dincel ${ }^{1}$,

${ }^{1}$ Gazi University, Faculty of Medicine, Department of Biochemistry, Ankara, Turkey

${ }^{2}$ Cyprus Health and Social Sciences University, Faculty of Dentistry, Güzelyurt, TRNC

Background: Teaching international students is a current and unique challenge of dental undergraduate education. This study was conducted to investigate the demographic background of a group of international students (i.e. students mainly from Middle Eastern countries), and to compare their academic success to other basic science subjects.

Materials and Methods: The study included the international students from Term I $(n=29)$ and II $(n=17)$ of Faculty of Dentistry, Cyprus Health and Social Sciences University. Biochemistry is taught for 2 hours (lectures) every week in the curriculum (academically oriented, theoretical). Students' academic performance was evaluated with quizzes, midterm and final exams.

Results: Overall, the study included 46 students $(58.7 \%, n=27$, male and $41.3 \%, n=19$, female). The demographic background of students were: $30,43 \%$ from Iran, $23,91 \%$ from Syria, $8,75 \%$ from Iraq and $6,55 \%$ from Egypt, 4,35\% from Jordan. The rest, 2,17\% came from other countries (Bahrain, Afghanistan, Pakistan, TC, USA, Germany, Lebanon and Palestine). According to the class variable of the sampling group, $58.1 \%$ of these students in Term 1 were successful and $56.2 \%$ of the students in Term 2 were successful.

The average succes of students for other basic science subjects were also similiar to biochemistry

Conclusion: Dentistry students in general perceive dentistry related courses as more important rather than basic science courses. Thus, biochemistry is not among the most favored subjects of dentistry students of Term 1 and 2. Although the international students having their classes in English, they have extra challenges due to language or adaptation problems. This reflects to their low academic success in these courses. Therefore, active and engaging teaching methods should be preferred not only to incraese the students success but also to improve the adaptation of international students in the classroom. Keywords: Biochemistry, Education, Descriptive Analysis

\section{PP-023 \\ MULTIDISCIPLINARY CASE-BASED SMALL GROUP DISCUSSIONS TO INTEGRATE BASIC MEDICAL SCIENCES WITH CLINICAL SITUATIONS}

Ilgi Semin ${ }^{1}$, Dilek Ersil Soysal ${ }^{2}$, Yasemin Seval Celik ${ }^{3}$, Murvet Hayran ${ }^{4}$, Ayse Banu Demir ${ }^{5}$, Ali Burak Ozkaya ${ }^{6}$, Sevinc V. Inan ${ }^{3}$, Gul Akdogan ${ }^{6}$ ${ }^{1}$ Izmir University of Economics, Faculty of Medicine, Department of Physiology, İmir, Turkey

${ }^{2}$ Izmir University of Economics, Faculty of Medicine, Department of Internal Medicine, İzmir, Turkey

${ }^{3}$ Izmir University of Economics, Faculty of Medicine, Department of Histology and Embryology, İzmir, Turkey

${ }^{4}$ Izmir University of Economics, Faculty of Medicine, Department of Anatomy, İzmir, Turkey

${ }^{5}$ Izmir University of Economics, Faculty of Medicine, Department of Medical Biology, İzmir, Turkey

${ }^{6}$ Izmir University of Economics, Faculty of Medicine, Department of Biochemistry, Izmir, Turkey

Background: Integration of the basic medical science with clinical medicine motivates medical students by showing how the fundamental concepts they have learned will come into their future practice. In this context, to improve team working and learning motivation of the students, we created clinical integrated sessions (CIS) in our first-year medical curriculum in the IEU School of Medicine, Izmir.

Materials and Method: The instructors of different disciplines wrote the clinical scenarios together. The scenarios were discussed in five sessions with 39 first-year students. The first session's scenario consisted of four brief "anemia" cases. However, the students preferred to discuss one case in each session. Therefore, the next four sessions included a single case. Students formed groups of 7-8 participants. In the first two hours, the scenarios were discussed in the groups and questions were answered by the students. In the third hour, the instructors answered the questions together with the students. After the first CIS, written feedback obtained from the students via a survey.

Results: The survey provided positive feedback on the benefits of active learning within small group discussions, and most of the students thought that their background was sufficient to solve the cases, with some literature search.

Conclusion: The scenarios, which provide multidisciplinary integration of basic medical sciences and clinical medicine, can be useful educational materials.

Key words: Small group discussion, multidisciplinary integration, basic medical sciences, clinical scenario 